\title{
STRONGYLOIDES STERCORALIS INFESTATION IN AN IMMUNOCOMPETENT HOST- A CASE REPORT
}

\author{
Sushma Kini ${ }^{1}$, Soorya $S^{2}$
}

${ }_{1}^{1}$ Assistant Professor, Department of Pathology, Government T. D. Medical College, Alappuzha, Kerala, India. ${ }^{2}$ Resident, Department of Pathology, Government T. D. Medical College, Alappuzha, Kerala, India.

HOW TO CITE THIS ARTICLE: Kini S, Soorya S. Strongyloides stercoralis infestation in an immunocompetent host- a case report. J. Evolution Med. Dent. Sci. 2018;7(22):2720-2722, DOI: 10.14260/jemds/2018/613

\section{PRESENTATION OF CASE}

A 59-year-old agriculturist with recent venture into poultry farming presented with history of post-prandial vomiting, gastric upset, loss of appetite and weight loss of 20 days duration. Investigations showed an $\mathrm{Hb}$ of $12 \mathrm{~g} \%$. Peripheral blood picture was WNL. HIV and HBsAg were negative and VDRL was non-reactive. USG abdomen was within normal limits. OGD scopy showed thick gastric rugae in fundus and body of stomach. There was antral erosion and the mucosa of duodenum showed nodularity. Biopsies were taken from fundus and body of stomach and first and second parts of duodenum.

\section{CLINICAL DIAGNOSIS}

Clinically, the patient was diagnosed as having carcinoma stomach.

\section{PATHOLOGICAL DISCUSSION}

Biopsies from body of stomach and first and second parts of duodenum were taken and showed infestation of the lamina propria by larval and adult forms of Strongyloides stercoralis along with lymphocytes, plasma cells and only a few eosinophils. Strongyloides larvae and adult worms were seen both within the crypts and surface epithelium.

The soil-transmitted helminth, Strongyloides stercoralis causes strongyloidiasis affecting an estimated $3-100$ million people in the world, mostly in tropical and subtropical countries.[1] Typically, the infection is asymptomatic or manifest as vague and non-specific gastrointestinal symptoms, hence, true prevalence of S. stercoralis is often underestimated. In immunocompromised patients, disseminated infestation of infective larvae is associated with high mortality rates.[1,2] Incidence of Strongyloidiasis has been reported as low in the Indian population [less than 1\%], especially, a heavy parasitic infestation. ${ }^{[3,4]}$ And there have been only few case reports, which have all termed the condition as rarity. $[2,3]$

'Financial or Other Competing Interest': None.

Submission 13-04-2018, Peer Review 11-05-2018,

Acceptance 17-05-2018, Published 28-05-2018.

Corresponding Author:

Dr. Sushma Kini,

Assistant Professor

Department of Pathology,

Government T. D. Medical College,

Alappuzha,

Kerala. India.

E-mail: drsushmakini@gmail.com

DOI: $10.14260 /$ jemds $/ 2018 / 613$
Strongyloides Stercoralis Infection encompasses Five Clinical Syndromes

1. Acute infection with Loeffler's syndrome.

2. Chronic intestinal infection.

3. Asymptomatic autoinfection.

4. Symptomatic autoinfection.

5. Hyperinfection syndrome (HS) with dissemination (DS).

The largest risk factor for acquiring S. stercoralis infection is visiting an endemic area.[1] Other predisposing factors are low socioeconomic status, rural occupations like agriculture, malnutrition, alcoholism, old age, immunocompromised conditions like therapy with corticosteroids, cyclosporine, and anti-cancer drugs, haematologic malignancies and infection with HIV and HTLV-1 viruses and rarely in persons taking PPIs chronically. $[4,5,6]$

It is usually asymptomatic in healthy hosts, but can rarely cause life-threatening hyperinfection.[3] Other common symptoms are dyspepsia, abdominal pain, bloating, diarrhoea, vomiting and small bowel obstruction as well as cough, wheezing and even pneumonia.[2]

Strongyloidiasis is difficult to diagnose, because the parasite load is low and the larval output is irregular.[7] Standard diagnostic methods include concentration techniques or stool culture method.[8] However, these methods are laborious, time consuming and labour intensive. Several immunological tests such as ELISA, IFAT and Western blot have also been described for the diagnosis of strongyloidiasis. ${ }^{[9,10]}$ Serology seems to lack sufficient sensitivity to diagnose recently acquired infections.[11] Although, initial diagnosis is usually suspected by suggestive history and peripheral eosinophilia and established by a routine stool examination, neither are sensitive tests and therefore EGD scopy with mucosal biopsy is vital for diagnosing Strongyloides infection. ${ }^{[4,5,12]}$ Endoscopic features include erythema, oedema, subepithelial haemorrhages, mucosal blebs or pseudopolyps, white villi, stenosis and megaduodenum.[4,12] Characteristic biopsy features are duodenitis, villous blunting and even atrophy, ulceration, crypt distortion, infiltration of the lamina propria with plasma cells and eosinophils and Strongyloides eggs, larvae and adult worms both within the crypts and the surface epithelium. $[4,6,12]$

It is uncommon to find this nematode infesting the stomach in an immunocompetent individual.[13,14]

In our case, an apparently healthy farmer presented with upper GI symptoms of short duration. OGD scopy showed thick gastric rugae in fundus and body of stomach, antral erosion, nodular mucosa of duodenum, all features highly suggestive of gastric malignancy. 


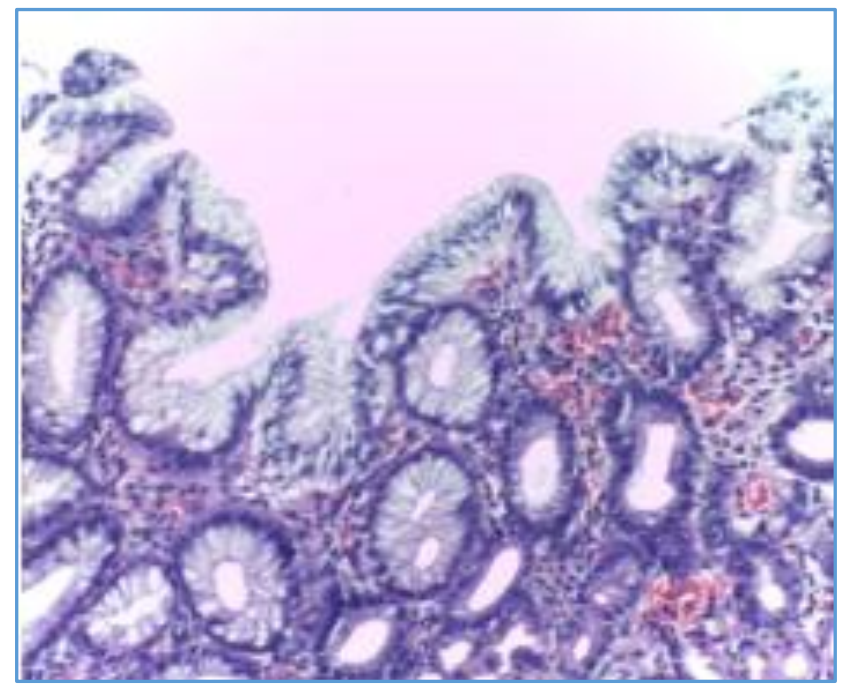

Figure 1. Biopsy from Fundus of Stomach showed No Specific Pathology

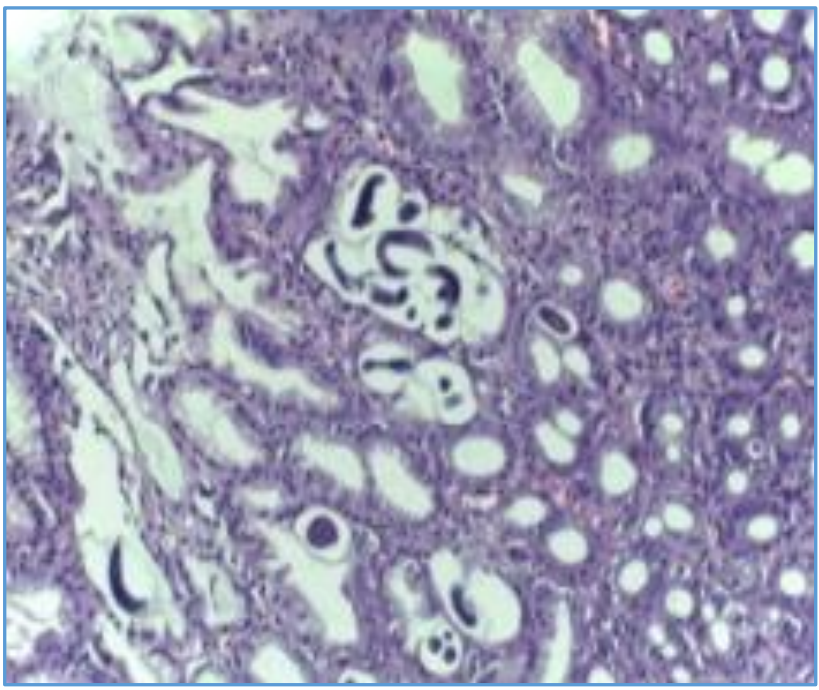

Figure 2. Biopsy from Body of Stomach demonstrated the Larval forms of Strongyloides Stercoralis

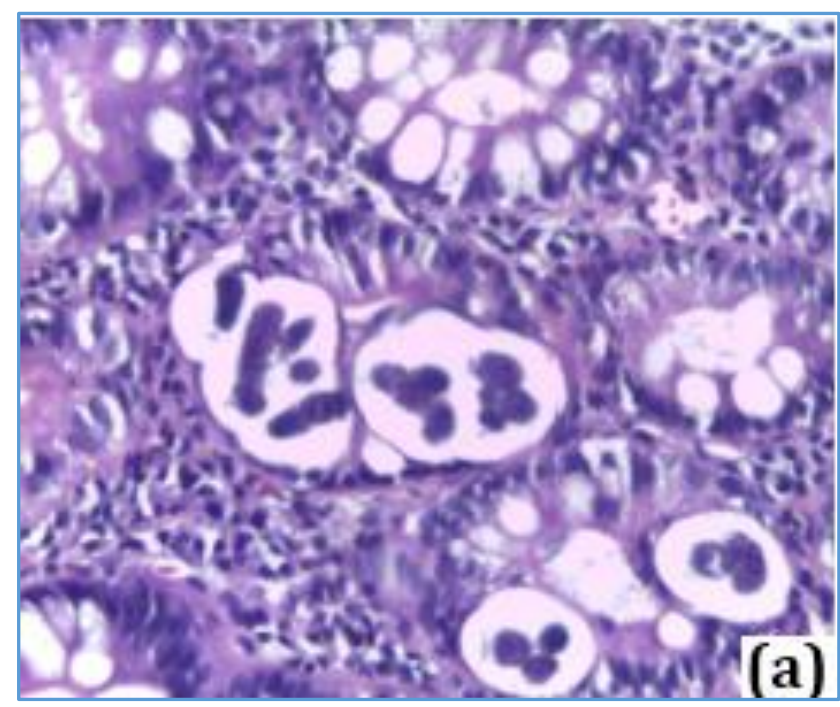

Figure 3 (a).

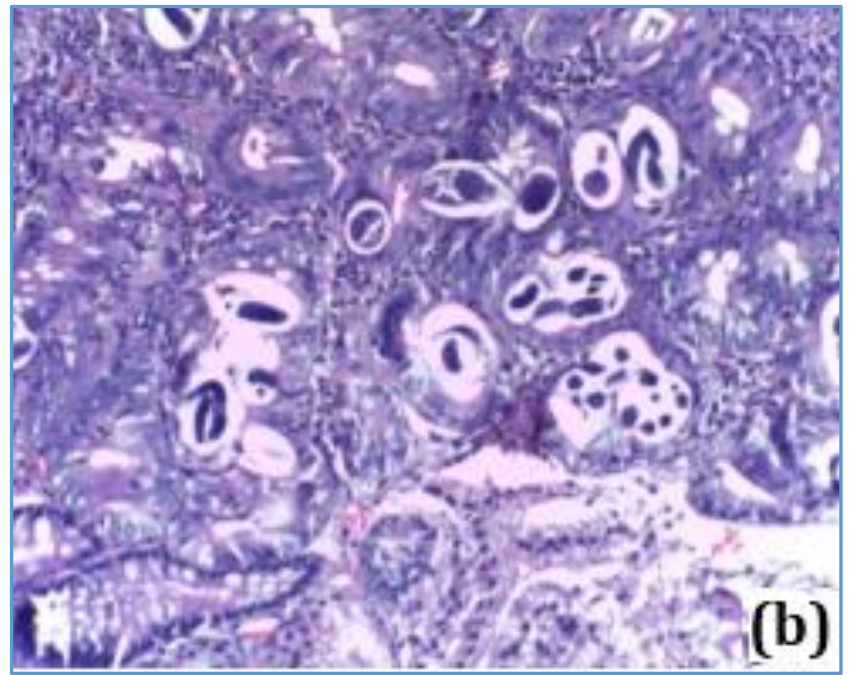

Figure 3 (a) and (b). Biopsies from D1 and D2 Parts of Duodenum showed Larval and Adult forms of Strongyloides Stercoralis

\section{DISCUSSION OF MANAGEMENT}

Since the patient presented with symptoms of dyspepsia of a short duration, he was being managed conservatively. Post biopsy, he developed vomiting which was managed with supportive measures. However, he had a massive episode of vomiting and succumbed on the second post biopsy day. An exact cause of death could not be ascertained.

It is seen that in patients receiving long-term corticosteroid therapy, malnutrition and immunocompromised, Strongyloidiasis leads to disseminated or hyperinfection syndrome resulting in mortality rates up to 87\%.[15]

This case is being reported due to the unusual presentation of widespread strongyloidiasis in an immunocompetent host from an as yet non-endemic region, which followed a stormy course leading to the death of the patient within two days of biopsy.

We would like to extend our heartfelt acknowledgement to Dr. Prasanth KS, Assistant Professor, Dept. of Medical Gastroenterology, Govt. TD Medical College, Alappuzha, for providing the necessary details needed to prepare the report.

\section{REFERENCES}

[1] Marcos LA, Terashima A, DuPont HL, et al. Strongyloides hyperinfection syndrome: an emerging global infectious disease. Transactions of The Royal Society of Tropical Medicine and Hygiene 2008;102(4):314-8.

[2] Mani RK, Sardana R, Chawla R, et al. Respiratory failure, coma and cutaneous lesions due to disseminated strongyloidiasis. Indian J Crit Care Med 2003;7(2):132-6.

[3] Cruz RJ, Vincenzi R, Ketzer BM. Duodenal obstruction an unusual presentation of Strongyloides stercoralis enteritis: a case report. World Journal of Emergency Surgery 2010;5:23.

[4] Kishimoto K, Hokama A, Hirata T, et al. Endoscopic and histopathological study on the Duodenum of Strongyloides stercoralis hyperinfection. World J Gastroenterol 2008;14(11):1768-73. 
[5] Satyanarayana S, Nema S, Kalghatgi AT, et al. Disseminated Strongyloides stercoralis in AIDS: a report from India. Indian $\mathrm{J}$ Pathol Microbiol 2005;48(4):472-4.

[6] Rivasi F, Pampiglione S, Boldorini R, et al. Histopathology of gastric and duodenal Strongyloides stercoralis locations in fifteen immunocompromised subjects. Arch Pathol Lab Med 2006;130(12):1792-8.

[7] Liu LX, Weller PF. Strongyloidiasis and other intestinal nematode infections. Infect Dis Clin North Am 1993;7(3):655-82.

[8] Cheesbrough M. Medical laboratory manual for tropical countries. Vol. 1. $2^{\text {nd }}$ edn. Cambridge: Tropical Health Technology and Butterworths 1987.

[9] Silva LP, Barcelos ISC, Passos-Lima AB, et al. Western blotting using Strongyloides ratti antigen for the detection of IgG antibodies as confirmatory test in human strongyloidiasis. Mem Inst Oswaldo Cruz 2003;98(5):687-91.

[10] Rodrigues RM, De Oliveira MC, Sopelete MC, et al. IgG1, IgG4, IgE antibody responses in human strongyloidiasis by ELISA using Strongyloides ratti saline extract as heterologous antigen. Parasitol Res 2007;101(5):1209-14.
[11] Sudarshi S, Stumpfle R, Armstrong M, et al. Clinical presentation and diagnostic sensitivity of laboratory tests for Strongyloides stercoralis in travellers compared with immigrants in a non-endemic country. Trop Med Int Health 2003;8(8):728-32.

[12] Thompson BF, Fry LC, Wells CD, et al. The spectrum of GI strongyloidiasis: an endoscopic-pathologic study. Gastrointest Endosc 2004;59(7):906-10.

[13] Sheth S, Asslo F, Hallit R, et al. Strongyloidiasis: the cause of multiple gastrointestinal ulcers in an immunocompetent individual. Case Reports in Medicine 2014;2014:346256.

[14] Prakash G, Gupta RK, Prakhya S, et al. Concurrent infection of candidiasis and strongyloidiasis in an endoscopic biopsy in an immunocompetent host. Indian J Pathol Microbiol 2011;54(3):644-5.

[15] Altintop L, Cakar B, Hokelek $M$, et al. Strongyloides stercoralis hyperinfection in a patient with rheumatoid arthritis and bronchial asthma: a case report. Ann Clin Microbiol Antimicrob 2010;9:27. 